\title{
Optimization of clear liquid fermentation condition for ethanol production from Canna edulis Kerl
}

\author{
Ying Shen, Qing-li Tang, Tian-Xiang Wu ${ }^{*}$ \\ College of Life Sciences,Guizhou University, Guiyang, China; ce.txwu@gzu.edu.cn
}

Received 27 October 2009; revised 24 November 2009, accepted 15 December 2009.

\begin{abstract}
In this paper, clear liquid fermentation condition for ethanol production from Canna edulis Kerl with orthogonal design was studied. We have studied five factors that influenced clear liquid fermentation condition for ethanol production from Canna edulis Kerl by the single-factor test. The five factors were $\alpha$-amylase amount, glucoamylase amount, $\mathrm{pH}$, nitrogen and auxiliary materials amount. Selected the best amounts of $\alpha$-amylase, glucoamylase, $\mathrm{pH}$, nitrogen source and auxiliary materials by means of the singefactors test. And then, we used the Orthogonal test to optimize the fermentation process. The study showed that the best fermentation conditions were $\alpha$-amylase amount $7 \mathrm{u} / \mathrm{g}$ C.eduli, glucoamylase amount $145 \mathrm{u} / \mathrm{g} \mathrm{C}$. edulis, $\mathrm{pH} 4.4$ and the amount of urea $0.08 \%, 1 \%$ of rice bran as auxiliary materials. The rate of alcohol which was produced by the best fermentation conditions is $21.5 \%$ that increased by $1.3 \%$ than the rate of alcohol by the single-factor test.
\end{abstract}

Keywords: Alcohol; Canna edulis Kerl ; Clear Liquid Fermentation; Orthogonal Design

\section{INTRODUCTION}

Canna edulis Kerl belongs to Cannaceae and Canna L, in chinese herbs it was called jiang-yu or jiao-ou. At the first of 20th century, it was planted widely at slope and hills in Sichuan, Guizhou and Yunan because of its excellent feature. The content of starch in rhizomes of Canna edulis Kerl is very abundant. The content of starch is about $40 \%-60 \%$ [8-13]. So Canna edulis Ker 1 has great development potential in supply of starch. The planting of Canna edulis Kerl can increase earning for montanic people. At the same time it has continuable-development significance in regulating agricul tural configuration and developing rural economics. But the starch of Canna edulis Kerl is made into noodle largely only now, so its value is low. The molecular structure and physical and chemical properties of the starch of Canna edulis Kerl were studied largely. Now, many scholars are investigating other purposes of the starch of Canna edulis Kerl. For exemple, the starch of Canna edulis Kerl has achieved a breakthrough in alcoholic fermentation. The solid-state fermentation, clear liquid fermentation of Canna edulis Kerl and the comprehensive utilization of fermentation residue have been researched largely in laboratory [1,7-11]. On this basis, we have got the best clear liquid fermentation process from Canna edulis Kerl with the single-factor test. Then we improve the utilization rate of Canna edulis Kerl raw after optimizing the technics of clear liquid fermentation condition for ethanol production from Canna edulis Kerl $[8,12,15,16]$.

\section{MATERIALS AND METHODS}

\subsection{Experimental Material}

Canna edulis Ker1: Collected from Xingyi Guizhou, the content of Starch is $60.1 \%$, the content of moisture is $14.8 \%$;

Thermal Resistance $\alpha$-amylase: wuxi xing-da BioEngineering Co., Ltd., enzyme activity: $20000 \mathrm{u} / \mathrm{mL}$;

New liquid glucoamylase: wuxi xing-da BioEngineering Co., Ltd., enzyme activity 100000u/Ml.

\subsection{Methods}

\subsubsection{The Preparation of Clear Liquid Culture Medium}

Firstly, mixed the powder of Canna edulis Kerl with water in a certain proportion, joined in $\alpha$-amylase, then heated them to $85 \sim 90^{\circ} \mathrm{C}$ rapidly, keep them together $30 \sim 60 \mathrm{~min}$. When the time was over, cooled them to $60^{\circ} \mathrm{C}$, adjusted $\mathrm{pH} 4.2$. A certain proportion moderate glucoamylase was joined into the mixture solution, a few minites later, the Solid-state glycation Saccharification dregs and clear liquid can be gained by centrifugal technology, then put the clear liquid into the autoclave whose 
tempreture was $121^{\circ} \mathrm{C}$, the clear liquid was taken out after twenty minutes. When the clear liquid tempreture fell to $30^{\circ} \mathrm{C}$, the yeast which was activated was inoculated into the clear liquid, the fermentation started in the incubator $[2,3]$.

\subsubsection{Determination of Alcohol Volume Fraction}

The clear liquid, which was the outcome of Canna edulis Kerl fermented, was measured $100 \mathrm{~mL}$ by measuring graduates $(100 \mathrm{~mL})$, inoculated into a rockered flask $(500 \mathrm{ml})$ which contained $100 \mathrm{~mL}$ distilled water. The distillation was collected by volumetric flask $(100 \mathrm{~mL})$, determined alcohol level by alcohol meter [4-6].

\subsubsection{Calculation of the Producing Ethanol Rate of Raw Materials and Starch Utilization [17]}

The producing ethanol rate of raw materials $=$

$$
\frac{95 \% \text { ethanol yield }(\mathrm{kg})}{\text { amount of raw materials }(\mathrm{kg})} \times 100 \%
$$

The starch utilization $=$

$$
\frac{\text { the actual liquor rate of starch }}{\text { the theoretical liquor rate of starch }} \times 100 \%
$$

\subsubsection{Determination of Reducing Sugar Concentration}

The distilled water was inoculated into the volumetric flask which contained separated clear liquid $0.1 \mathrm{~mL}$ till $25 \mathrm{~mL}$. The mixed solution was determinated for reducing sugar concentration by DNS analytical method [5].

\subsubsection{Determination of Mass Concentration of Total Sugar}

The distilled water was inoculated into the volumetric flask which contained separated clear liquid $0.1 \mathrm{~mL}$ till $25 \mathrm{~mL}$. The mixed solution was determinated for total sugar concentration by $\mathrm{H}_{2} \mathrm{SO}_{4}$-Pheuol analytical method [5].

\section{RESULTS AND ANALYSIS}

\subsection{Single-Factor Test and Medium Optimization}

Based on former experiments, we have found the best solid-state fermentation conditions of the ethanol production from Canna edulis Kerl, the best conditions were ratio of material to water $1: 2.2, \alpha$-amylase amount $5 \mathrm{u} / \mathrm{g}$ C.edulis, liquefaction time $45 \mathrm{~min}$, glucoamylase amount $150 \mathrm{u} / \mathrm{g}$ C.edulis, saccharification time $23.2 \mathrm{~min}$, $\mathrm{pH} 5.5$, urea $0.1 \%$, fermentation temperature $27.9{ }^{\circ} \mathrm{C}$, ADY $0.15 \%$, fermentation time $48 \mathrm{~h}$ and inert carrier $1 \%$.

On this basis, the paper studied the clear liquid fermentation conditions of the ethanol production from
Canna edulis Kerl. By a large number of experiments, we found that $\alpha$-amylase amount, glucoamylase amount, $\mathrm{pH}$ and urea amount have an important influence on the whole fermentation technology.

So we were proceeding to the in-depth study for these four factors, these studies as follows:

\subsubsection{The Effect of $\alpha$-amylase Amount on the Alcohol Fermentation}

In order to confirm the appropriate amount of $\alpha$-amylase on clear liquid fermentation from Canna edulis Kerl, different amount of $\alpha$-amylase were tested on the ethanol rate of raw materials (Canna edulis Kerl) [7-11,14]. The results were showed in Figure 1.

The Figure 1 showed that when the $\alpha$-amylase amount was $6 \mathrm{u} / \mathrm{g}$ C.edulis, the ethanol rate of raw materials (Canna edulis Kerl) was highest. So the conclusion was $\alpha$-amylase amount $6 \mathrm{u} / \mathrm{g}$ was the best condition on clear liquid fermentation for ethanol production from Canna edulis Kerl.

\subsubsection{The Effect of Glucoamylase Amount on the Alcohol Fermentation}

Glucoamylase played an important role in the clear liquid fermentation for ethanol production from Canna edulis Kerl, it can influence the cost of production. Different glucoamylase amount were tested on the ethanol rate of raw materials [7-11].

The different results were revealed in Figure 2.

The Figure 2 described that when the glucoamylase amount exceeded $150 \mathrm{u} / \mathrm{g}$, the ethanol rate of raw materials (Canna edulis Kerl) was steady. In order to cut down the consumption of glucoamylase, the glucoamylase amount $150 \mathrm{u} / \mathrm{g}$ was appropriate on clear liquid fermentation for ethanol production from Canna edulis Kerl.

\subsubsection{The Effect of Different pH Conditions on Alcohol Fermentation}

The $\mathrm{pH}$ of Clear Liquid fermented were adjusted to 3.6, 4.2, 4.5, 5.0 and 6.0 (the pH of Canna edulis Kerl Glycosylated liquid was original) [7-11]. The outcomes were dr-

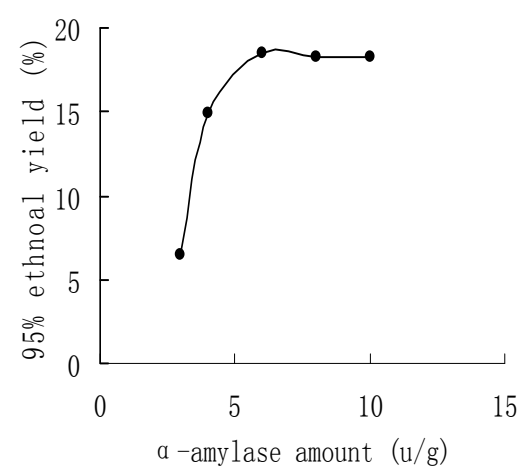

Figure 1. The effect of $\alpha$-amylase amount on the alcohol fermentation. 


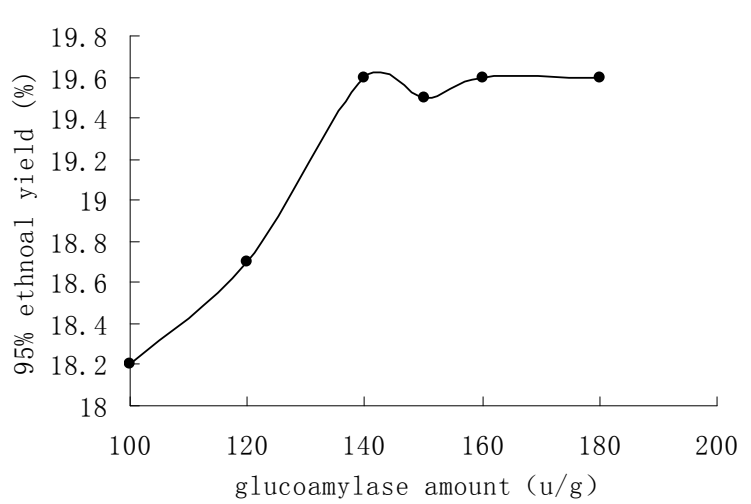

Figure 2. The effect of glucoamylase amount on the alcohol fermentation.

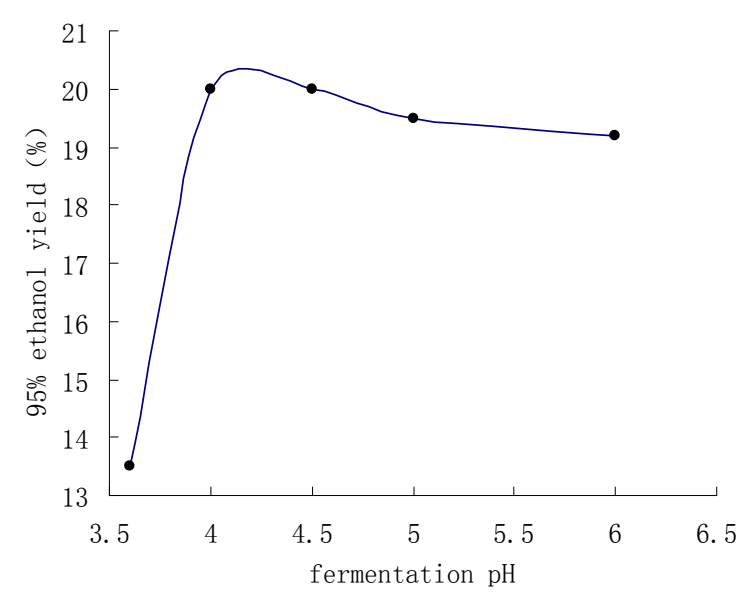

Figure 3. Effect of $\mathrm{pH}$ on ethanol fermentation.

ew in Figure 3.

The conclusion can be ascertained: the yield of alcohol was gradual increasing when $\mathrm{pH}$ was 3.5 to 4.2 . When $\mathrm{pH}$ was 4.2 to 6.0 , the yield of alcohol had a basically stable situation and the best effect was $\mathrm{pH} 4.2$.

\subsubsection{The Effect of Nitrogen on the Alcohol Fermentation}

Under suitable environment and nutritional conditions, yeast can bear alcohol in high concentration, but the vigour of yeast was lower when nitrogen was scarce in culture medium. In this article, the yeast was restrained because the amount of nitrogen was deficient in glycosylated liquid. For accelerating growth of yeast and enhancing the ability of alcohol-resistant yeast, a certain amount of nitrogen was necessary to be added in the culture medium. With an eye to the results were various because of different nitrogen, therefore, urea, ammonium sulfate, ammonium bicarbonate, peptone and yeast extract were choiced as the element inspected in this experiment. The amount of nitrogen must be based on $0.1 \%$ nitrogen content of urea, the nitrogen content of urea, ammonium sulfate, ammonium bicarbonate, pep- tone and yeast extract were $46.7 \%, 20 \%, 17.7 \%, 13.5 \%$, $7 \%$ respectively. The outcomes were shown in Figure 4.

It was found that five kinds of nitrogen had great influence on alcohol fermentation from Canna edulis Kerl although urea showed the best consequence, maybe it can protect some enzymes, for example the alcohol dehydrogenase, promoted the activity of enzyme.

In order to confirmed the best amount of urea, at the next experiment, different dosage of urea which were $0.05 \%, 0.1 \%, 0.15 \%, 0.2 \%$ and $0.3 \%$ were studied on clear liquid fermentation condition for ethanol production from Canna edulis Kerl at the same condition. The results were revealed in Figure 5.

It was showed that the rate of alcohol reduced gradually from $0.15 \%$ to $0.3 \%$ dosage of urea, the rate of alcohol rised steadily from 0 to $0.1 \%$ dosage of urea. The best data appeared at $0.1 \%$ dosage of urea.

\subsubsection{The Effect of Inert Carrier on Alcohol Fermentation}

Fine-Grained material maybe reduce the content of $\mathrm{CO}_{2}$ which could suppress yeast colony, different content of bran and corn cob were tested respectively on ethanol

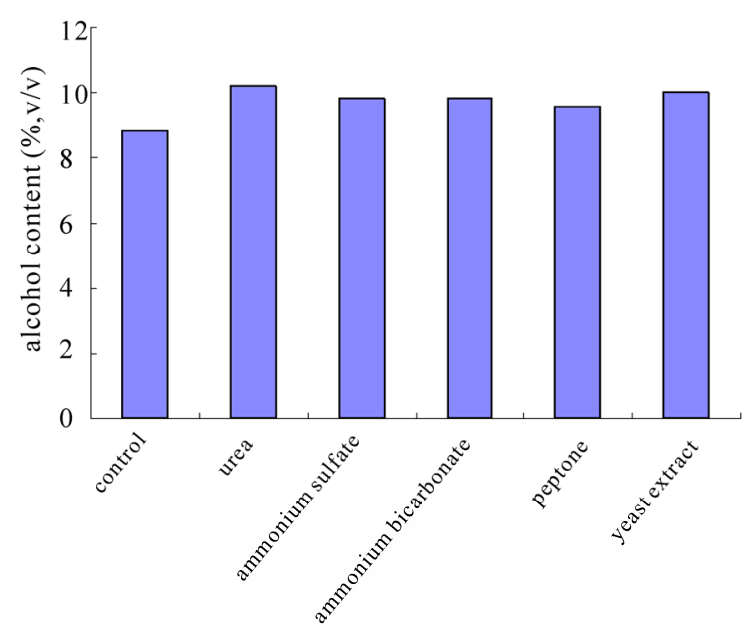

Figure 4. The effect of nitrogen on alcohol fermentation.

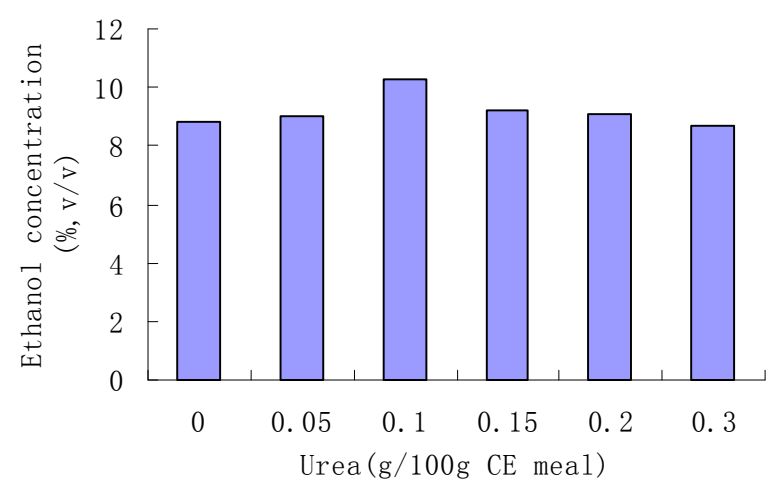

Figure 5. Effect of urea concentration on ethanol fermentation. 


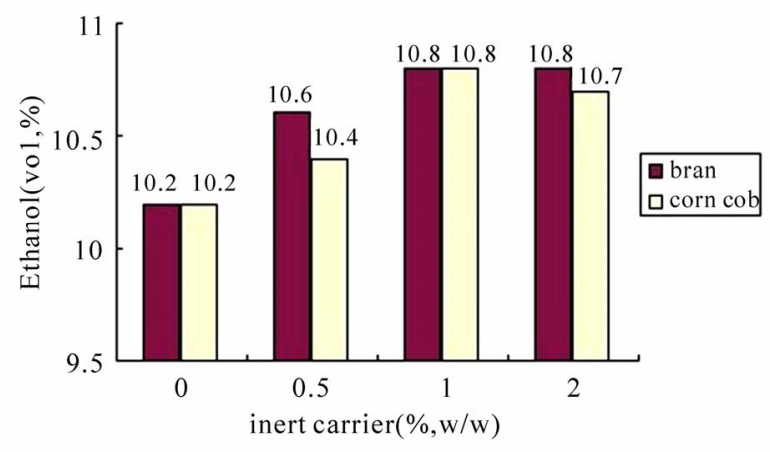

Figure 6. Effect of inert carrier on ethanol fermentation.

fermentation. The content of them were $0,0.5 \%, 1 \%, 2 \%$ respectively. The results were showed in Figure 6.

The diagram indicated that bran and corn cob can promote alcohol fermentation of Canna edulis Kerl. 1\% bran had the best effect. The same information had been reported in other documents.

\subsection{Orthogonal Test}

According to the results of the single-factor test, $\alpha$-amylase amount, glucoamylase amount, $\mathrm{pH}$ and the amount of urea were optimizated by orthogonal experiment $[8,12,15]$.

The $\alpha$-amylase amount $6 \mathrm{u} / \mathrm{g}$ C.edulis, glucoamylase amount $150 \mathrm{u} / \mathrm{g}$ C.edulis, $\mathrm{pH} 4.2$ and the amount of urea $0.1 \%$ were used as intermediate level in the orthogonal tests. The experimental design and results of analysis were showed in Table 1, Table 2 and Figure 7 (In the Table 1 and Table 2, A, B, C and D stand for the

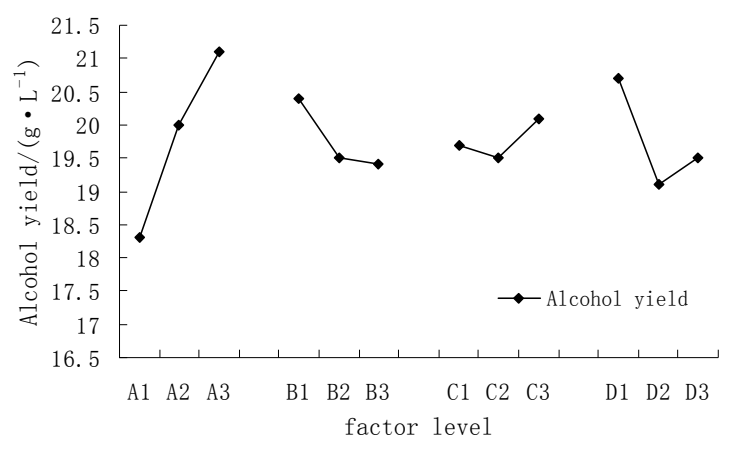

Figure 7. The trend of factors and indexs in orthogonal experiment.

$\alpha$-amylase amount, glucoamylase amount, $\mathrm{pH}$ and urea amount respectively. In the Tables $\mathbf{1}$ and $\mathbf{2}$ stand for three different amount levels of the four factors respectively.)

The Table 2 showed that $\alpha$-amylase amount had a great influence on clear liquid alcohol fermentation of Canna edulis Kerl. Based on the results of experiment, the influence of the other factors on the clear liquid alcohol fermentation of Canna edulis Kerl were ordered from larger to little as the amount of urea $>$ gluco $\alpha$ mylase amount $>\mathrm{pH}$.

As can be seen from Figure 7, the best combination was $A_{3} B_{1} C_{3} D_{1}$, that is to say, the $\alpha$-amylase amount $7 \mathrm{u} / \mathrm{g}$ C.edulis, the glucoamylase amount $145 \mathrm{u} / \mathrm{g}$ C.edulis, $\mathrm{pH}$ 4.4 , and the amount of urea $0.08 \%$.

At last, after three parallel experiments which have been carried out on ethanol fermentation by the optimal

Table 1. Factor and level of orthogonal experiment.

\begin{tabular}{ccccc}
\hline level & $\alpha$-amylase amount $(\mathrm{u} / \mathrm{g})$ & $\begin{array}{c}\text { glucoamylase amount } \\
(\mathrm{u} / \mathrm{g})\end{array}$ & $\mathrm{pH}$ & 0.08 \\
& & 145 & 4.0 & 0.1 \\
2 & 5 & 150 & 4.2 & 0.12 \\
3 & 6 & 155 & 4.4 & the amount of urea $(\%)$ \\
\hline
\end{tabular}

Table 2. Results and analysis of orthogonal experiment.

\begin{tabular}{|c|c|c|c|c|c|}
\hline Test No. & \multicolumn{4}{|c|}{ factor } & Alcohol yield $(\%)$ \\
\hline 1 & 1 & 1 & 1 & 1 & 19.8 \\
\hline 3 & 1 & 3 & 3 & 3 & 18.0 \\
\hline 4 & 2 & 1 & 2 & 3 & 20.1 \\
\hline 5 & 2 & 2 & 3 & 1 & 2.0 \\
\hline 7 & 3 & 1 & 3 & 2 & 21.3 \\
\hline 8 & 3 & 2 & 1 & 3 & 20.5 \\
\hline 9 & 3 & 3 & 2 & 1 & 21.4 \\
\hline mean 1 & 18.3 & 20.4 & 19.7 & 20.7 & \\
\hline mean 2 & 20.0 & 19.5 & 19.5 & 19.1 & \\
\hline mean 3 & 21.1 & 19.4 & 20.1 & 19.5 & \\
\hline
\end{tabular}


technological conditions, we found the production rate of alcohol were $21.7 \%, 21.4 \%, 21.5 \%$ respectively, and the average was $21.5 \%$.

\section{CONCLUSIONS}

1) Canna edulis Kerl is a non-alimentarn crop. The advantages of fuel ethanol produced by Canna edulis Kerl were raising the utilization rate of resources, reducing the pollution of the environment, lower manufacturing Cost and higher productivity. The fuel ethanol produced from Canna edulis Kerl can not only solve the problem of food security, but also promote the development of fuel alcohol industry in china.

2) We have known that $\alpha$-amylase amount, glucoamylase amount, $\mathrm{pH}$, nitrogen and auxiliary materials can influence clear liquid fermentation for ethanol production from Canna edulis Kerl. Then optimizing four factors by the orthogonal test .The best process conditions are $\alpha$-amylase amount $7 \mathrm{u} / \mathrm{g}$ C.edulis, glucoamylase amount $145 \mathrm{u} / \mathrm{g}$ C.edulis, $\mathrm{pH} 4.4$, the amount of urea $0.08 \%$ and $1 \%$ of rice bran. The production rate of alcohol was $21.5 \%$ which increased by $1.3 \%$ than the production rate of alcohol by the single-factor test.

3) We are researching the best conditions of clear liquid fermentation for ethanol production from Canna edulis Kerl. These investigations laid a good foundation for reducing the cost of alcohol production, comprehensive utilization of Resources and efficient, saving, undefiled technics of alcohol production. So clear liquid fermentation for ethanol Production from Canna edulis Kerl was an epoch-making event in the realm of industrial alcohol.

\section{REFERENCES}

[1] Zhu, Z.H. and Wu, T.X. (2005) Studies on characters and industral applications of Canna edulis Kerl starchy materia1 [J]. Chinese Journal of Bioprocess Engineering, 3(4), 66-70.

[2] Fang, S.Q., Zhao, Y.f., Niu, Q.C. et al. (2005) Study on the technology of alcohol production by wheat flour clear liquid [J]. Liquor-Making Science \& Technology, 5, 64-65.

[3] Liu, L.F. and Ma. X.J. (2004) Study on alcoholic fermentation from wheat hourin clarifying solution [J]. Chinese Journal of henan institute of education (Natural
Science Edition), 13(4), 57-58.

[4] Wang, F.R. (1980) Analysis of industrial fermentation [M]. Beijing;China Light Industryb Press, 25-27.

[5] Wang, F.R. (2006) Bio-engineering analysis and detection [M]. Beijing: China Light Industryb Press, 140-163.

[6] Zhang, K.C. (2004) Alcohol and tequila-technology [M]. Beijing; China Light Industryb Press.

[7] Wu, T.X., Ding, C.Y., Yang, H.1. et a1. (2003) Study on teclmology of the semi-solid state pulp fermentation of Canna edulis Eerl for ethanol [J]. Liquor Making, 30(2), 71-73.

[8] Fang, Y., Wang, P.H., Xie, S.Q. et al. (2004) Technique of scarifying and fermenting process of canna starch [J]. Southwest China Journal of Agricultural Sciences, 17(2), 231-234.

[9] Wu, T.X., Zhang, K.C., Liu, C.Z. et a1. (2005) Study on the property of canna edulis ker \& its application in ethanol fermentation [J]. Liquor-Making Science \& Technology, 10, 40-42.

[10] Wu, T.X., Ding, C.Y., Yang, H.L. et al. (2002) The feasibility study on the solid state fermentation and the development of alcoholic industry [J]. Food and Fermentation Industries, 28(12), 67-70.

[11] Chen, Y.F., Fang, H.Y., Wang, Z.G. et al . (2002) Study on flask ethanol fermentation conditions of Canna edulis Kerl [J]. Liquor Making, 29(6), 63-65.

[12] Ying, B., Qu, J.Q. and Lin, X.M. (2005) Principles of microbial technology development [M]. Chemical Industry Press, (3), 99-109.

[13] Thitipraphunkul, K., Uttapap, D., Piyachomkwan, K. and Takeda, Y.A. (2003) Comparative study of edible canna (Canna edulis) starch from diferent cultivars Part I, Chemical composition and physicochemical properties [J]. Carbohydrate Polymers, 53, 317-324.

[14] Shigechi, H., Fujita, Y., Koh, J., Ueda, M., Fukuda, H. and Kondo, A. (2004) Energy-saving direct ethanol production from low-temperature-cooked corn starch using a cell-surface engineered yeast strain co-displaying glucoamylase $\alpha$-amylase [J]. Biochem EngJ, 18, 149-153.

[15] Bandaru, V.V.R., Somalanka, S.R., Menduc, D.R., Madicherla, N.R. and Chityala, A. (2006) Optimization of fermentation conditions for the production of ethanol from sago starch by co-immobilized amyloglucosidase and cells of Zymomonas mobilis using response surface methodology [J]. Enzyme Microb Technol, 38, 209-14.

[16] Yan, L, and Shuzo, T. (2006) Ethanol fermentation from biomass resources: current state and prospects [J]. Appl Microbiol Biotechnol, 69, 627-642.

[17] Zhu, Z.H., Zhang, H.Y. and Wu, T.X. (2007) Response surface methodology to optimize ethanol fermentation from Canna edulis Ker [J]. Liquor-Making Science \&Technology, 8, 29-32. 